\title{
FORMANDO COMPETÊNCIA PELA CONEXÃO INTERDISCIPLINAR E TRANSDISCIPLINAR POR MEIO DE PROJETOS INTEGRADORES NO SENAI/SC ${ }^{1}$
}

\author{
BUILDING COMPETENCE FOR THE INTER-DISCIPLINARY AND \\ TRANS-DISCIPLINARY CONEXION THROUGH INTEGRATORS \\ PROJECTS AT SENAI/SC
}

\author{
Cleunisse Rauen De Luca Canto \\ SENAI/SC - Florianópolis \\ E-mail: cleo@ctai.senai.br \\ Juliano Anderson Pacheco \\ DIGITRO / SENAI/SC - Florianópolis \\ E-mail: jap@ctai.senai.br
}

\begin{abstract}
Resumo. Atualmente o SENAI/SC adota a metodologia baseada na educação por competência, e trabalha com Projetos Integradores (PI) nos seus Cursos de Graduação e Técnico como uma ferramenta interdisciplinar e transdisciplinar efetiva para a formação através do princípio "saber fazer". Os PIs são projetos teórico-práticos apresentado por meio de requisitos que fazem com que os alunos apliquem os conhecimentos adquiridos, com isto desenvolvendo as competências básicas, específicas e de gestão relacionadas ao seu perfil profissional. É uma estratégia de ensino-aprendizagem desenvolvida como um instrumento facilitador no processo e que permite disponibilizar uma proposta padrão de avaliação cognitiva, com regras e procedimentos pré-definidos, que aperfeiçoam e unificam os conhecimentos adquiridos no decorrer do ano letivo. O intuito deste artigo é, portanto, fundamentar o processo ensino-aprendizagem para, a partir de então, apresentar o PI como uma ferramenta efetiva para medir conhecimentos, habilidades e atitudes dos alunos nos Cursos do SENAI/SC.
\end{abstract}

Palavras-chaves: Projeto integrador; Competências; Aprendizagem significativa

Abstract. Currently SENAI/SC adopts a methodology based upon education by competence, and works with Integrators Projects (IP) in its Graduation and Technical Courses acting as inter-disciplinary and trans-disciplinary tools effective for the formation through the "Know How to Do" principle. PIs are theoretical-practical projects presented by means of requirements that encourage the students at applying the acquired knowledge, developing, through this, the basic competences, specific and managerially related to their professional profile. It is a teaching-learning strategy developed as an instrument aimed at easing the process and that permits to offer a standard proposition of evaluation of knowledge, with predefined rules and procedures that improve and unify the knowledge acquired during the year of lectures. The aim of this article is, therefore, to lay the foundations of the teachinglearning process and, starting from now, to present PI as an effective tool to measure knowledge, abilities and attitudes of the students in the courses of SENAI/SC.

Keywords: Integrator Project; Competencies; Significant Learning 


\title{
1 INTRODUÇÃO
}

Considera-se pertinente afirmar que, para que uma aprendizagem ocorra, esta deve ser significativa. De acordo com Pelizzari et al. (2002, p. 2),

\begin{abstract}
A aprendizagem é muito mais significativa à medida que o novo conteúdo é incorporado às estruturas de conhecimento de um aluno e adquire significado para ele a partir da relação com seu conhecimento prévio. Ao contrário, ela se torna mecânica ou repetitiva, uma vez que se produziu menos essa incorporação e atribuição de significado, e o novo conteúdo passa a ser armazenado isoladamente ou por meio de associações arbitrárias na estrutura cognitiva.
\end{abstract}

De acordo com Alvarez (2001), uma pessoa aprende o que ouve depois de ter apreciado o que vê. O que ouve depende do que vê, e o que vê depende do que mexe e experimenta.

Ao se levar o aluno a registrar, identificar, criar e explorar permite-se uma organização lógica do pensamento e as novas metodologias tornam-se aliadas neste processo, pois garantem a construção e a aquisição do conhecimento de uma forma mais dinâmica, portanto mais prazerosa (TAFNER; FISCHER, 2001).

Se o docente deseja alcançar resultados eficazes com a sua intervenção nas situações de aprendizagem, deve, ao planejá-las, planejar, também, a sua intervenção mediadora, isto é, elaborar questões que se constituam em fio condutor de seu ato de mediação. A mediação da aprendizagem é uma estratégia que não permite improvisações. É um trabalho complexo, fundamentado na reflexão e no planejamento.

É oportuno considerar também que, com a continuidade do trabalho de mediação, o aluno adquirirá mais autonomia em relação ao seu aprendizado e o docente observará que a sua intervenção torna-se menos necessária. O resultado desejado é que o aluno, ao longo de sua aprendizagem mediada, aprenda a mediar-se diante de situações novas e consiga perceber a relevância dos processos interdisciplinares envolvidos na educação (FEUERSTEIN, 1980).

Começa a surgir, em meados de 90 do século XX, então, o modelo de educação voltado para o ensino não mais por conteúdo, mas por competência (SOUZA, 2005). Um modelo de educação que se pauta na apreensão de conhecimentos necessários para o sujeito atuar, intervir e interagir nessa chamada sociedade da informação que muda constantemente. Este sujeito deverá ser capaz de mobilizar seus saberes, valores e habilidades para solucionar problemas. Por isso, a denominação de competência, concebida como a capacidade de utilizar os conhecimentos e as habilidades adquiridas para o exercício profissional (DECRETO-LEI 5154/2004).

As questões que mobilizaram este artigo, portanto, baseiam-se no pôster da IX Jornada Catarinense de Educação e Tecnologia (JORNATEC) apresentado por Pacheco, Rasche e Canto (2007) que estão no alicerce e permeiam a experiência de construir competências na educação tecnológica das Faculdades de Tecnologia do Serviço Nacional de Aprendizagem Industrial (SENAI) de Santa Catarina (SC). Dentre os objetivos dos cursos oferecidos consta: "formar profissionais qualificados para o exercício de atividades produtivas, oferecendo um ensino em que se combinem competências e habilidades mediante programas que estejam constantemente adaptados às necessidades presentes e futuras da sociedade" (SISTEMA 
FIESC, 2005, p. 10).

Com base nas noções de formação por competências estabelecidas por Perrenoud (1999), o método de ensino-aprendizagem apóia-se nos três pontos principais: Conhecimento, Habilidades e Atitudes (CHA). Conhecimento é ciência, é um saber sistematizado. A noção de habilidades perpassa por ações e funções necessárias à profissão e podem ser vistas como capacidades. As atitudes/valores envolvidos na construção das competências definem a postura que o profissional deverá demonstrar para trabalhar.

Conforme ressaltaram Pacheco, Rasche e Canto (2007), no pôster da Jornatec, nos currículos das Faculdades de Tecnologia SENAIsc o Conhecimento é o escopo da Unidade Curricular (UC) em estudo, as Atitudes são as iniciativas para obter êxito na aprendizagem e as Habilidades compreendem o resultado do processo, onde o aluno adquire condições para executar uma determinada atividade de forma diferenciada, demonstrando ter Competência. Desta forma, uma ferramenta adotada é o desenvolvimento do Projeto Integrador (PI), que neste artigo fundamenta-se por estar vinculado ao processo ensino-aprendizagem numa educação por competências. Educação esta permeada de incertezas no campo avaliativo e que busca na experiência e vivencia pessoal dos alunos desenvolver estratégias que auxiliem no aperfeiçoamento de todo um processo que se mostre eficiente e possa garantir um perfil profissional moldado dentro das característica que o mercado busca.

\section{REFERENCIAL TEÓRICO}

O processo de ensino e aprendizagem não é, como se tornou senso comum, um processo único (ensino-aprendizagem). De acordo com Weiz (2002), são dois processos distintos que se complementam e interagem, mas sem perder a sua especificidade.

O grande desafio metodológico a ser enfrentado pelos professores e estudantes em relação ao processo ensino-aprendizagem é a mudança de paradigma. O uso de situações desafiadoras promove a aprendizagem significativa e o estudante aprende a lidar com o novo adquirindo cada vez mais autonomia (PELIZZARI et al., 2002).

O processo de aprendizagem pode ser definido de forma sintética como o modo que os seres adquirem novos conhecimentos, desenvolvem competências e mudam o comportamento. Segundo Moreira (1999), a "[...] aprendizagem significativa é um processo por meio do qual uma nova informação relaciona-se, de maneira substantiva (não-literal) e não-arbitrária, a um aspecto relevante da estrutura de conhecimento do indivíduo"2 Em outras palavras, os novos conhecimentos adquiridos pelos alunos relacionam-se com seus conhecimentos prévios, sendo estes mais ou menos abrangentes dependendo da freqüência com que a aprendizagem significativa ocorre.

Assim, quando se busca uma aprendizagem significativa, que considera as diferenças individuais, que reflete contextos reais, que privilegia o fazer e o porquê se faz de determinada forma, que estimula a criatividade e a autonomia, então se faz necessário que os ambientes escolares correspondam a esses objetivos.

De acordo com Piaget (1983) a construção do conhecimento advém de ações físicas ou mentais que acontecem sobre objetos que, provocando o desequilíbrio ${ }^{3}$, resultam em assimilação $^{4}$ ou, acomodação ${ }^{5}$ dessas ações e, assim, a construção de esquemas ou conhecimento $^{6}$. Em outras palavras, uma vez que uma pessoa não consegue assimilar o 
estímulo ela tenta fazer uma acomodação, para após uma assimilação, daí então o equilíbrio é alcançado.

A aprendizagem é, portanto, decorrente de uma "equilibração" entre assimilação, acomodação e organização, levando a crer que as dificuldades de aprendizagem se tornam presentes quando alguma interferência se manifestar nesse processo. No entanto, toda "equilibração" é provisória. A interação sujeito-objeto de conhecimento está sempre em movimento gerando novas "desequilibrações" que, por sua vez, levarão a novas "equilibrações" e assim sucessivamente (CANTO, 2004).

As situações de aprendizagem, ao serem construídas, devem ter em vista evocar no aluno seus saberes já internalizados. Todo professor, além de ser um especialista nos conteúdos que leciona, precisa saber como se processa a aprendizagem na mente humana e quais estratégias podem garantir uma aprendizagem significativa.

Conhecer conteúdos sem saber a maneira de intermediar sua construção pelo aluno é como conhecer a fórmula de um remédio sem saber seus efeitos sobre a patologia para o qual ele foi criado (SENAI, 2006).

Leituras mais recentes de aprendizagem, vinculadas a Psicologia e as ciências da_Educação, definem o ENSINAR e o APRENDER A PENSAR como um processo contínuo e pessoal de construção de conhecimento por parte do aluno (AUSUBEL, 1962).

De acordo com Almeida (1993), a escola tem sabido mais exigir as destrezas de atenção, de raciocínio e de estudo, do que criar oportunidades efetivas para sua aquisição e treino.

Os teóricos mais recentes do desenvolvimento cognitivo e da aprendizagem, segundo Elkind (1982), afirmam que nada aprendemos por "colagem" e tudo o que é retido por mera justaposição, substituição ou memorização mais tarde acabará por desaparecer, sem nunca ter sido devidamente integrado na estrutura do conhecimento do indivíduo.

Ser capaz de pensar e de aprender é competência fundamental ao trabalho e sucesso escolar do aluno. Os professores teriam de estar preparados para este treino, favorecendo com isto a aquisição e a destreza de tais competências cognitivas. Nesta perspectiva, cabe ao professor compreender o caminho de aprendizagem que o estudante percorre e, em função disso, identificar as informações e as atividades que lhes permitam avançar do patamar em que se encontra para outro mais complexo. É o ensino que deve se adaptar à aprendizagem, mantendo um diálogo com ela.

Em consonância com os pressupostos abordados, a mediação pedagógica se apresenta como possibilidade metodológica capaz de apoiar uma aprendizagem significativa. Neste contexto insere-se a mediação como uma proposta metodológica que parte do pressuposto de que o professor, o estudante e a situação de aprendizagem interagem entre si.

De acordo com Feuerstein (1980), o professor age como mediador quando consegue ficar lado a lado do estudante e mobilizar critérios de mediação para complementar e enriquecer o processo de aprendizagem.

De acordo com Vygotsky (1989), a mediação incide sobre o que ele chamou de "Zona de Desenvolvimento Proximal", que é a distância entre o nível de desenvolvimento real e o nível de desenvolvimento potencial do aluno. O nível de desenvolvimento real é representado 
pelo modo como o estudante consegue resolver, sozinho, as situações apresentadas, já o nível de desenvolvimento potencial representa o modo como o estudante é capaz de resolver situações apresentadas com a mediação do professor para atingir o seu potencial.

O desenvolvimento destes critérios garante uma modalidade de mediação voltada para a metacognição, onde o aluno é levado a pensar (e verbalizar) sobre seus próprios processos de pensamento, assim como suas habilidades para controlar esses processos mediante sua organização, realização e modificação.

Depresbiteris (1998) enfatiza que, para o desenvolvimento da metacognição existem duas fases básicas. A primeira diz respeito à tomada de consciência de uma estrutura de saber por parte de quem aprende, pois é estimulado a colocar em prática os raciocínios já desenvolvidos, a criar "métodos de pensar" mais elaborados, a levantar hipóteses, a fazer inferências, a abstrair. Essa estimulação do pensamento é feita por um mediador. A segunda, desenvolvida em longo prazo, conduz a maior consciência nas formas de pensar a resolução de um problema. Essa tomada de consciência requer que a pessoa lance mão dos raciocínios necessários para resolver os problemas.

$\mathrm{Na}$ verdade, a metacognição faz-se notória quando a própria pessoa é capaz de mediar suas formas de pensar e agir. Assim, podemos afirmar que a ênfase dos processos de ensino e de aprendizagem deve estar relacionada com o mundo do trabalho e considerar o contexto sociocultural para, então, garantir o desenvolvimento de capacidades que levem ao domínio de competências.

Para Perrenoud (1999, p. 7) competência pode ser conceituada como a "[...] capacidade de agir eficazmente em um determinado tipo de situação, apoiada em conhecimentos, mas sem limitar-se a eles".

De acordo com o Conselho Nacional de Educação (2002) ser competente profissionalmente implica na "[...] capacidade pessoal de mobilizar, articular e colocar em ação conhecimentos, habilidades, atitudes e valores necessários para o desempenho eficiente e eficaz de atividades requeridas pela natureza do trabalho e pelo desenvolvimento tecnológico".

O conceito de competências implica, portanto, na capacidade de mobilizar conhecimentos para a ação. Em diferentes situações, para agir é preciso desenvolver habilidades, e a atitude aparece como um fator motivacional, ou seja, é o modo como o conhecimento e sua habilidade são efetivamente postos em prática (ANTUNES, 2001).

Desenvolver o ser humano não é só desenvolvê-lo para agir em sociedade, é desenvolvê-lo para a felicidade, o que significa também desenvolver plenamente suas potencialidades.

No discurso da competência é um engano dizer que o saber fazer se sobrepõe ao conhecer. Na verdade, o conhecimento não perde sua validade e importância, mas este deverá ser intermediado no sentido de favorecer a compreensão dos problemas efetivando a capacidade de ação diante da necessidade de tomada de decisões e resolução de problemas, seja no âmbito produtivo ou cidadão (ANTUNES, 2001).

As novas pedagogias acreditam que o aluno envolvido e interessado aprende com uma energia incompatível. Por isso é preciso tornar os saberes significativos e interessantes. O aluno precisa compreender o real valor do que está sendo trabalhado e acreditar nisso para que 
compreenda com total clareza a importância com que conhecimentos e saberes se articulam na vida real.

Costa (2002) enfatiza que, ser competente é ter capacidade de mobilizar conhecimentos com vistas à tomada de decisão e resolução de problemas diante de uma realidade complexa. Efetivar um projeto de educação por competências requer promover um novo tipo de comportamento diante da vida e dos fatos. Desse modo, a prática pedagógica deve deslocar o foco dos conteúdos para a lógica das competências, o que exige uma prática pedagógica reflexiva.

Perrenoud (1999) destaca que desenvolver competências na escola significa relacionar constantemente os saberes e sua operacionalização em situações complexas. De certa forma quer dizer que no ambiente escolar, o estudante será preparado para acionar sua base de conhecimento, experimentando quando possível fazê-lo, mas, sobretudo preparado para no momento oportuno atuar de acordo com seu aprendizado com vista ao que pede a realidade.

Assim, Canto e Rasche (2007) consideram que ao exercer a prática pedagógica reflexiva com vistas a um projeto de educação por competência requer do docente, ultrapassar os limites da sala de aula buscando o conhecimento que está sendo aplicado na realidade, visando desenvolver a consciência crítica dos alunos. Nesse sentido, as atividades devem ser orientadas a apresentar forte contextualização e correlação com a realidade, com vistas à aplicação de conteúdos efetivamente significativos. Nessa perspectiva educacional, o aluno deverá desenvolver uma postura ativa, expondo dúvidas, explicitando raciocínios, com vistas a ter consciência do seu aprendizado de forma crítica e autônoma.

De um modo geral, pode-se dizer que, na formação profissional baseada em competências busca-se desenvolver um comportamento orientado pela qualificação técnica e profissional capaz de agir na e sobre a realidade com base em conhecimento, seja cientifico tecnológico ou oriundo da experiência prática.

De acordo com Elking (1982), a verdadeira aprendizagem acontece quando a integração da informação chega ao quadro mais lato daquela informação que já possui. Só nessa altura podemos falar em aprendizagem como construção de conhecimento.

A teoria de processamento da informação pressupõe que a aprendizagem envolva os conhecimentos que o sujeito já possui, ou seja, interaja com sua memória de longo prazo. Só assim estamos em face de uma aprendizagem significativa e de tipo construtivista, na qual o conhecimento anterior joga um papel importante (ALMEIDA 1992).

Alvarez (2002) salienta que “[...] nossa mente está equipada com dois tipos básicos de memória: a imediata, para tratar a informação do presente momento; e a de longo prazo, para arquivar durante longo tempo [...]" (p.17), e que memória:

[...] é a capacidade de armazenamento de todas as formas de conhecimento adquirido por nós em nossas relações com o meio ambiente. É a capacidade de aprender coisas novas, relacioná-las com informações já guardadas e tirar novas conclusões, das quais nos lembraremos depois.

[...] é a capacidade de fixar, conservar em latência e reproduzir, evocar ou representar as impressões sensoriais recebidas, transmitidas e conscientizadas sob a forma de sensações. (ALVAREZ, 2007, p. 17) 
Pode-se dizer, então, que a memória é a base do raciocínio. Ao chamar ou rechamar a informação, o cérebro está apto a combiná-la e a organizá-la. Não se combina o que não se conserva; daí o papel integrativo da memória, função indispensável à análise, seleção, conexão, síntese, formulação e regulação das informações necessárias à elaboração, planificação e execução de comportamentos.

Machado (2002) pontua que, quanto mais a abstração sobre um tema for relacionada a múltiplos contextos, mais fecundo é o aprendizado. Quando se trata de dado conhecimento, cabe ao professor explorar com os alunos situações no qual este se aplica ou pode vir a ser aplicado. Esse talvez seja um exercício de inventividade e criatividade. Explorar as condições para efetivar dada idéia, as variáveis que tendem a interferir ou não, as possibilidades de sucesso ou de fracasso, tudo isso colabora para efetivar a prática educativa com vistas ao desenvolvimento de competências.

Quando se busca a contextualização rompe-se com a disciplinaridade. Nesse caso, busca-se a chamada interdisciplinaridade. A interdisciplinaridade toma por base a noção de que o homem e o mundo são indivisíveis, muito embora não percebamos assim. Recortamos a realidade para compreendê-la, porém, a dinâmica que busca estabelecer relações e compreender o todo é necessária para evitar visões unilaterais ou que estão dissociadas da realidade.

A interdisciplinaridade quando chegou ao Brasil já exerceu influência na elaboração da Lei de Diretrizes e Bases $N^{\circ} 5.692 / 71$. Desde então, sua presença no cenário educacional brasileiro tem se intensificado e, recentemente, mais ainda, com a nova LDB $\mathrm{N}^{\circ}$ 9.394/96 e com os Parâmetros Curriculares Nacionais (PCN). Segundo os Parâmetros Curriculares Nacionais:

\footnotetext{
A interdisciplinaridade supõe um eixo integrador, que pode ser o objeto de conhecimento, um projeto de investigação, um plano de intervenção. Nesse sentido, ela deve partir da necessidade sentida pelas escolas, professores e alunos de explicar, compreender, intervir, mudar, prever, algo que desafia uma disciplina isolada e atrai a atenção de mais de um olhar, talvez vários (BRASIL, 2002, p. 88-89).
}

Quando falamos em práticas pedagógicas interdisciplinares em escolas estamos buscando uma pedagogia que visa uma inter-relação entre todos os profissionais envolvidos no processo educacional. A interdisciplinaridade é o ponto chave e fundamental para o trabalho desenvolvido com as diferentes habilidades operatórias e estes nos apresentam como sugestão a educação por competências.

Por meio da interdisciplinaridade, o processo de avaliação do ensino-aprendizagem na educação por competências avança do "saber que" para o "saber como". Ambos constituem tipos de conhecimentos a serem exigidos dos alunos. Assim, os mecanismos de avaliação deverão ser orientados a testar capacidades no sentido de utilizar o que aprenderam. $\mathrm{O}$ docente pode e deve elaborar uma ou mais situações de aprendizagem desafiadoras, considerando a complexidade do que será desenvolvido. Neste caso, a situação deve "dar conta" dos fundamentos e/ou capacidades selecionadas, devendo, ainda, estar contextualizada com as competências apontadas pelo perfil profissional, referência para o desenho curricular do curso.

Nessa concepção educativa a realidade serve como um acervo, um laboratório, permitindo formular e reformular situações problemas com o intuído de aprimorar os conhecimentos pessoais com vistas a uma ação competente. Desta forma distanciando-se da idéia de que "O 
aluno acumula saberes, passa nos exames, mas não consegue usar o que aprendeu em situações reais" (PERRENOUD, 2000, p.19).

Os processos de aprendizagem não estão desligados dos processos de ensino implementados pelos professores. Aprendizagens mais profundas ou significativas se conseguem por meio de métodos de ensino-aprendizagem que possibilitem e reforcem a iniciativa do aluno, o seu sentido de descoberta e uma construção de conhecimento a partir da análise e resolução de problemas concretos ${ }^{7}$.

Segundo Rezende; Tronca; Tronca (2004) exige-se da nossa escola uma reciclagem profunda, uma postura inovadora para que se possa transformar os alunos em trabalhadores modernos, que possuam conhecimento de trabalho em equipe, capacidade de adaptar-se rapidamente à mudanças e às novas tecnologias, além da habilidade para resolver problemas e tomar decisões com rapidez e independência.

Ressalta-se, portanto, que a educação é tida hoje como um grande desafio para qualquer nação, e para o Brasil é certamente um problema básico e que condiciona nossa perspectiva de futuro. As mudanças que estamos assistindo são tantas, que se torna cada vez mais difícil sobreviver neste novo mundo sem habilidades e competências necessárias. A educação se torna cada vez mais importante, pois ela fornece a medida do indivíduo, da comunidade e da nação. Sendo assim, a inter-relação entre os processos significativos para o ensinar e o aprender garantem ao aluno a construção de um conhecimento integrado com o desenvolvimento das competências básicas e de gestão consideradas essenciais para o perfil profissional exigido pelo mercado de trabalho.

\section{PROCEDIMENTOS METODOLÓGICOS}

A arte de educar está em pesquisar melhorias para o sistema ensino-aprendizagem. Pesquisa é, portanto, o "[...] esforço dirigido para aquisição de um determinado conhecimento, que propicia a solução de problemas teóricos, práticos e/ou operativos mesmo quando situados no contexto do dia-a-dia do homem" (RAUEN, 2002).

Uma ferramenta adotada para tal, nos cursos de graduação tecnológica da Faculdade é o desenvolvimento do Projeto Integrador (PI). Nestes, são propostos focos de trabalho sintonizados com as Unidades Curriculares (UC) e, consequientemente, com as Competências trabalhadas durante o ano em questão. O projeto é desenvolvido pelos alunos, em equipes, com o objetivo de atingir um escopo básico de um projeto. Concretamente, os alunos recebem, ou sugerem, um problema de ordem prática para resolver, e têm que desenvolver um projeto aplicando os conhecimentos, habilidades e atitudes trabalhadas no decorrer do ano letivo, demonstrando assim competência na área de formação.

O desenvolvimento do projeto culmina na elaboração de um instrumento que permita acompanhar o processo ensino-aprendizagem e analise os conhecimentos, as habilidades e as atitudes adquiridos pelos alunos quando da realização de um projeto interdisciplinaridade que, literalmente, avalie as competências desenvolvidas. A apresentação oral do mesmo aos colegas de sala e professores serve para validar a interdisciplinaridade da proposta.

É importante considerar que o planejamento concretizado para uma Unidade Curricular pode e deve ser realizado para um conjunto delas, de modo que a situação de aprendizagem seja suficientemente complexa para assumir as características de projeto integrador. A grande 
vantagem desse tipo de situação é a busca da interdisciplinaridade, evitando que o aluno obtenha uma visão fragmentada do currículo.

\section{RESULTADOS}

Com o desenvolvimento dos Projetos Integradores nos Cursos do SENAIsc espera-se entender como, efetivamente, se processou o desenvolvimento e a aquisição do conhecimento no aluno. A partir de então, identifica-se quais estratégias foram utilizadas nas diferentes unidades curriculares para estabelecer critérios vinculares entre as formas de validação destas, visando a interdisciplinaridade de todo o processo.

O resultado esperado neste processo culmina com a idéia principal de utilizar uma metodologia auxiliar que permita ajudar para que o perfil profissional dos alunos esteja diretamente vinculado ao que o mercado de trabalho busca, explorando os conhecimentos, as habilidades e, principalmente as atitudes dos alunos. Por meio deste instrumento avaliativo é possível identificar a base que contempla todos os parâmetros vinculares do processo ensinoaprendizagem e nos permite aplicar conceitos coerentes com as reais capacidades de cada um.

Com tal proposta, busca-se subsídios suficientes para que o desenvolvimento da pesquisa ocorra dentro do mais eficiente modelo de aprendizado para o aluno e, todos os professores envolvidos no processo não devem medir esforços em fornecer os conhecimentos necessários visando, assim, uma melhoria no desempenho e obtenção dos dados.

\section{CONSIDERAÇÕES FINAIS}

Segundo Pacheco, Rasche e Canto (2007) verificou-se que o PI permite ampliar competências de forma transversal, onde os alunos são orientados no desenvolvimento de uma aplicação prática, ou seja, uma pesquisa voltada para a área de formação, levando a efetiva interdisciplinaridade. Além disso, destacam os autores, o PI desperta no aluno o interesse pela pesquisa, uma vez que o mesmo culmina numa defesa com constituição de banca, entrega de um trabalho escrito (com revisão bibliográfica), dentro dos padrões de publicação de trabalhos científicos (ABNT), apresentação oral do projeto desenvolvido, envolvendo o conteúdo teórico e a aplicação.

O mais importante é que o aluno, ao término desta atividade, além de demonstrar as habilidades adquiridas, conseguiu resolver um problema de interesse pessoal, através da idealização e materialização de uma solução, geralmente com muita criatividade, tornando realidade o que antes existia no campo das idéias, unindo as Competências trabalhadas em duas ou mais Unidades Curriculares.

\section{REFERÊNCIAS}

\section{ALMEIDA, L. S. Rentabilizar o ensino-aprendizagem escolar para o sucesso e o treino} cognitivo dos alunos. Vila Nova de Gaia: EdiPsico, 1993.

ALMEIDA, L. S. Facilitar a aprendizagem: ajudar os alunos a aprender a pensar. Rev. Psicologia Escolar e Educacional, Campinas, v.6, n.2, Dec. 2002. Disponível em: $<$ http://pepsic.bvs-psi.org.br/scielo.php?script=sci_arttext\&pid=S1413-

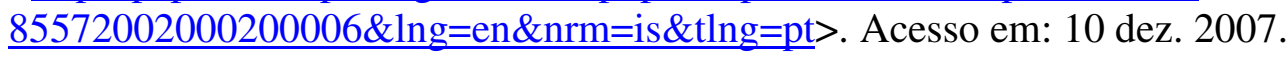


ALVAREZ, A. M. M. A. Processamento auditivo central: causas, diagnóstico e aplicações. Palestra. Florianópolis, 2001.

ALVAREZ, A. M. M. A. Deu Branco: um guia para desenvolver o potencial da sua memória. São Paulo: Ed. Best Seller, 2002.

ANTUNES, C. Trabalhando habilidades: construindo idéias. São Paulo: Scipione, 2001.

AUSUBEL, D. P. A aprendizagem significativa: a teoria de David Ausubel. São Paulo: Moraes, 1982.

BRASIL. Ministério da Educação. Secretaria de Educação Média e Tecnológica. Parâmetros Curriculares Nacionais: Ensino Médio. Brasília: Ministério da Educação, 2002.

BRASIL. Decreto-Lei de Diretrizes e Bases da Educação Básica. Decreto 5.154 de 23 de julho de 2004, Brasília, 2004.

CANTO, C. R. De L.; RASCHE, F. Metodologia do Ensino Superior. Florianópolis: SENAIsc Florianópolis/CTAI, 2007. [Apostila].

CANTO, C. R. De L. Distúrbio do Processamento Auditivo Central numa visão Psicopedagógica: um estudo de caso. 2004. 176f. Dissertação (Mestrado) - Psicopedagogia Clínica e Institucional, Universidade do Sul de Santa Catarina, Florianópolis.

CONSELHO Nacional de Educação, 2002.

COSTA, C. O. da. Educação profissional: dos conteúdos programáticos às competências profissionais. Porto Alegre: Unidade Estratégica de Desenvolvimento Educacional SENAI/RS, 2002.

DESPRESBITERIS, L. Avaliação da aprendizagem do ponto de vista técnico-científico e filosófico-político. Série Idéias, São Paulo - FDE, n. 8, p. 161-172, 1998.

ELKIND, D. Crianças e adolescentes. Rio de Janeiro: Zahar Editores, 1982.

FEUERSTEIN, R. An Instrumental Enrichment: an intervention program for cognitive modificability. Baltimore: University Park Press, 1980.

MACHADO, N. J. Sobre a idéia de competência. In. PERRENOUD, P. et al. As competências para ensinar no século XXI: a formação dos professores e o desafio da avaliação. Porto Alegre: Artmed, 2002. p. 137-155.

MOREIRA, M. A. Teorias de aprendizagem. São Paulo: Editora Pedagógica e Universitária Ltda., 1999. Disponível em: <http://pt.wikipedia.org/wiki/Aprendizagem_significativa>. Acesso em: 10 dez. 2007.

PACHECO, J. A.; RASCHE, F.; CANTO, C. R. De L.. Formando competência pela integração interdisciplinar e transdisciplinar, IX Jornada Catarinense de Educação Tecnológica, Florianópolis, 2007. [Pôster]. 
PELIZZARI, A. et al. Teoria da aprendizagem significativa segundo Ausubel. Revista Educação - PEC, Curitiba, v.2, n.1, p.37-42, jul. 2001/jul. 2002.

PERRENOUD, P. Avaliação: da excelência à regulação das aprendizagens - entre duas lógicas. Porto Alegre: Artmed, 1999.

PERRENOUD, P. 10 novas competências para ensinar. Porto Alegre: Artmed, 2000.

PIAGET, J. Psicologia da inteligência. 2. ed. Rio de Janeiro: Zahar, 1983.

RAUEN, F. J. Roteiros de investigação científica. Tubarão: Unisul, 2002. 268p.

REZENDE, E. S.; TRONCA, G.; TRONCA, F. Z. Philippe Perrenoud: em busca de uma nova maneira de ensinar. Tubarão: Unisul, 2004.

SENAI Departamento Nacional. Documento Norteador de práticas pedagógicas: formação com base em competências. Brasília: SENAI DN, 2006.

SISTEMA FIESC. SENAI Santa Catarina. Regimento interno da Faculdade de Tecnologia SENAI Florianópolis. Florianópolis, 2005.

SOUZA, D. B. A escola como empresa: sinonímia do pragmatismo e tecnicismo. In: QUARTIERO, E. M.; BIANCHETTI, L.o (Org.). Educação corporativa: a nova fase/fase das relações entre universidade e empresa. São Paulo: Cortez, 2005.

TAFNER, M. A.; FISCHER, J. Manga com leita mata: reflexões sobre os paradigmas da educação. Indaial: Editora da ASSELVI, 2001.

VYGOTSKY, L. S. A formação social da mente. São Paulo: Martins Fontes, 1989.

WEIZ, Telma. O diálogo entre o ensino e a aprendizagem. São Paulo: Editora Ática, 2002.

1 Trabalho apresentado inicialmente como pôster na IX Jornada Catarinense de Educação Tecnológica, Florianópolis, 2007, posteriormente fundamentado pela autora principal.

\footnotetext{
${ }^{2}$ Disponível, também, em: <

${ }^{3}$ É o processo da passagem de uma situação de menor equilíbrio para uma de maior equilíbrio. Uma fonte de desequilíbrio ocorre quando se espera que uma situação ocorra de determinada maneira, e esta não acontece.

${ }^{4}$ Processo pelo qual o indivíduo cognitivamente capta o ambiente e o organiza possibilitando, assim, a ampliação de seus esquemas. Processo cognitivo de colocar (classificar) novos eventos em esquemas existentes; incorporação de elementos do meio externo a um esquema ou estrutura do sujeito. Na assimilação o indivíduo usa as estruturas que já possui.

${ }^{5}$ Modificação de um esquema ou de uma estrutura em função das particularidades do objeto a ser assimilado. Pode ser a criação de um novo esquema ou modificação de um já existente de modo que o estímulo possa ser incluído nele. Após acomodação, tenta-se novamente encaixar o estímulo no esquema e aí ocorre a assimilação. Por isso, a acomodação não é determinada pelo objeto e sim pela atividade do sujeito sobre este, para tentar assimilá-lo.
} 
${ }^{6}$ São as estruturas mentais ou cognitivas pelas quais os indivíduos intelectualmente organizam o meio. Modificam-se com o desenvolvimento mental e tornam-se cada vez mais refinadas e mais apta a generalizar os estímulos. Os esquemas cognitivos do adulto são derivados dos esquemas sensório-motores da criança e, os processos responsáveis por essas mudanças nas estruturas cognitivas são assimilação e acomodação.

${ }^{7}$ Informação obtida de <scielo.bvs-psi.org.br/scielo.php?script=sci_arttext...02000200006\&lng=pt\&nrm=is>.

Originais recebidos em: 28 fev. 2008.

Texto aprovado em: 20 mar. 2008.

\section{SOBRE OS AUTORES}

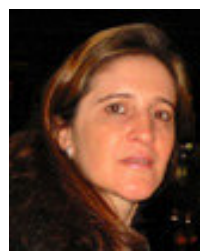

Cleunisse

Rauen De Luca Canto

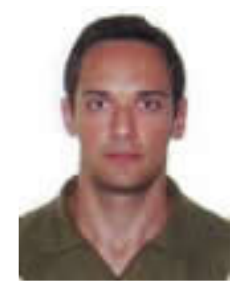

Juliano

Anderson Pacheco
Possui graduação em Pedagogia com Habilitação em Magistério (1988) e Supervisão Escolar (1989) pela UDESC. Aperfeiçoamento de estudos em Análise de Sistema (ACEI, 1992), especializaçao em Educaçao de Adultos por meio do Programa de Educaçao à Distância do SENAI/DR/SC e mestrado em Psicopedagogia Clìnica e Institucional pela UNISUL (2004). Atualmente é Coordenadora Pedagógica do SENAIsc Florianópolis (CTAI), Professora da Faculdade Energia em Administração e Negócios, Professora Convidada da Pós-Graduação na Escola de Aperfeiçoamento Profissional da Associaçao Brasileira de Odontologia (ABO/EAP) e Professora da PósGraduação do Instituto Catarinense de Pós-Graduação (ICPG Sul, Vale e Litoral). Tem experiência na área de Educação, com ênfase em Ensino-Aprendizagem, Metodologia do Ensino Superior e Processos Diagnósticos para Avaliaçao Psicopedagógica.

E-mail: cleo@ctai.senai.br

Possui graduação em Engenharia Elétrica pela Universidade Federal de Santa Catarina (1997) e mestrado em Ciências da Computação pela Universidade Federal de Santa Catarina (2005). Atualmente atua no departamento de Marketing da Dígitro Tecnologia, na área de Inteligência de Mercado e, também, como Coordenador do curso superior de Tecnologia em Telecomunicações na Faculdade SENAI/Florianópolis. Tem experiência na áreas de Telecomunicações e Ciência da Computação, com ênfase em Sistemas de Informação, Redes Convergentes, Análise Estatística de Dados e Geoprocessamento. E-mail: jap@ctai.senai.br 